\title{
Late-Onset Mirror Syndrome
}

\author{
Erinna Mohamad Zon, Nik Ahmad Zuky Nik Lah, Pek Sung Hoo
}

Zon EM, Nik Lah NAZ, Hoo PS. Late-Onset Mirror Syndrome. Malays Fam Physician. 2021;16(1);129-132. https://doi.org/10.51866/cr1099

\section{Keywords:}

Mirror syndrome, Ballantyne

syndrome, hydrops fetalis

\section{Authors:}

\section{Erinna Mohamad Zon}

(Corresponding author)

MD (USM), MMed O\&G (USM)

Department of Obstetrics \&

Gynaecology, School of Medical

Sciences, Universiti Sains Malaysia

Malaysia

Department of Obstetrics \&

Gynaecology, Hospital Universiti

Sains Malaysia, Malaysia

Email: erinna@usm.my

\section{Nik Ahmad Zuky Nik Lah} MD (USM), MMed O\&G (USM) Department of Obstetrics \& Gynaecology, School of Medical Sciences, Universiti Sains Malaysia Malaysia

\section{Hoo Pek Sung}

MD (UKM) MRCOG (UK)

Department of Obstetrics \&

Gynaecology, School of Medical

Sciences, Universiti Sains Malaysia Malaysia

\section{Abstract}

Mirror syndrome is a rare clinical condition in pregnancy associated with significant fetal mortality and maternal morbidity. It is characterized by a triad of complications: fetal hydrops, placenta oedema, and maternal oedema. We are reporting one case of late-onset Mirror syndrome in which the patient presented later in the gestation of 36 weeks due to excessive weight gain and clinical sign mimicking preeclampsia. Awareness of this disease is essential, as a failure of recognition will delay the treatment and cause higher maternal and perinatal morbidity and mortality

\section{Introduction}

Mirror syndrome is a rare clinical condition in pregnancy associated with significant fetal mortality and maternal morbidity. It is characterized by a triad of complications: fetal hydrops, placenta edema, and maternal edema. The reason for discussing this case is to highlight the high fetal mortality risk associated with this condition.

\section{Case Report}

A 29-year-old housewife in her third pregnancy at 36 weeks gestation was referred from a district hospital for severe preeclampsia when she presented with hypertensive crisis with headache and high proteinuria. Previously, she had been normotensive, non-proteinuric and all her antenatal follow-ups had been uneventful. Her serial ultrasound was completed and no gross abnormality was detected, with no evidence of fetal growth restriction. Four days before her presentation, she was noted to have an excessive weight gain of $7.5 \mathrm{~kg}$ in two weeks with prominent bilateral pedal edema and proteinuria and she was planned for blood pressure monitoring at a local clinic. During monitoring, the physician noted her blood pressure was high and she was referred to a tertiary center for severe preeclampsia. Assessment of the patient upon admission noted that she had anasarca, high blood pressure, and high proteinuria. Her uterus was larger than the gestational age. Ultrasound examination revealed a singleton fetus with breech presentation and generalized hydrops (scalp edema (Figure 1), pleural effusion, pericardial effusion, ascites (Figure 2), and generalized skin edema). The fetus also had cardiomegaly with atrioventricular cushion defect and a constricted right ventricular outflow (Figure 3). There was also a hyperplancentosis with a placenta thickness of $12.29 \mathrm{~cm}$ (Figure 4).
She was diagnosed with mirror syndrome and was started on magnesium sulfate infusion for the prevention of eclampsia. Her condition was stable, but the fetal prognosis was poor. The patient was then counseled for vaginal delivery with an induction of labor. She had an assisted vaginal breech delivery and a fresh stillbirth 3 $\mathrm{kg}$ female baby with edema and peeled skin was born (Figure 5). The placenta weight was $1.8 \mathrm{~kg}$ (Figure 6).

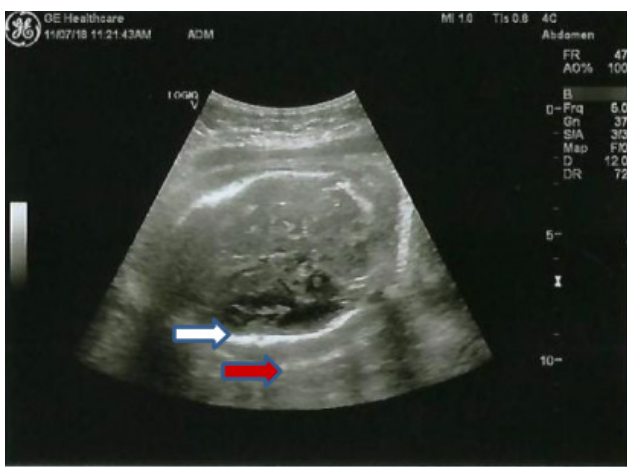

Figure 1: Transabdominal scan finding of scalp edema (white arrow: skull, red arrow: scalp). There was fluid collection in between these two structures.

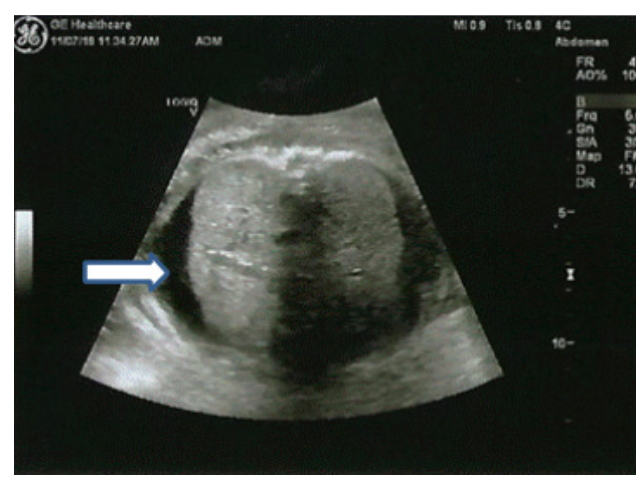

Figure 2: Transabdominal scan of fetal ascites (white arrow) and fluid accumulation in the abdominal cavity. 


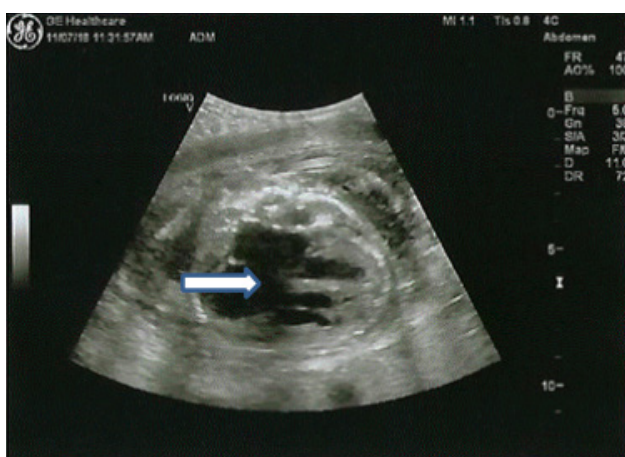

Figure 3: Transabdominal scan finding of cardiomegaly with atrioventricular cushion defect (white arrow).

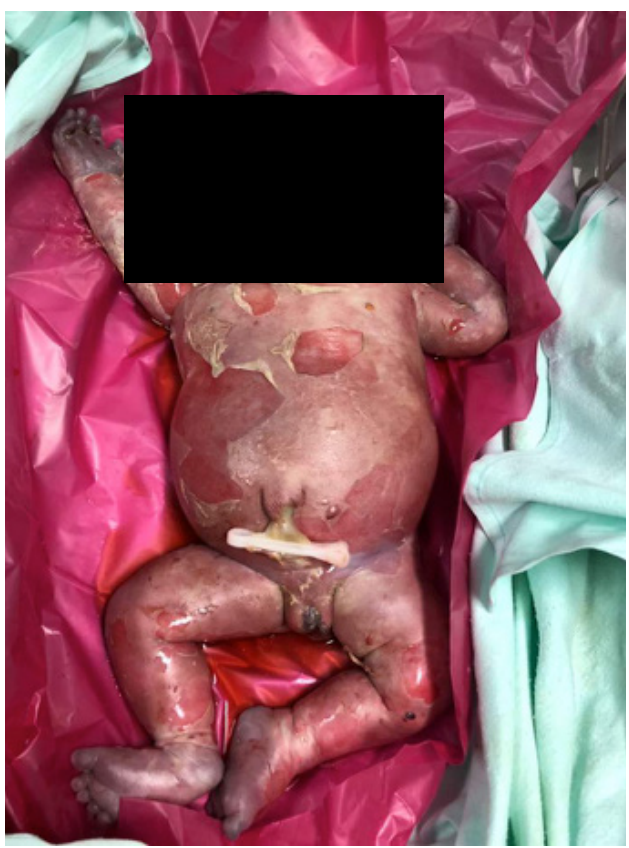

Figure 5: Hydrops fresh stillbirth with generalized skin edema and peeling of the skin.

She had massive primary postpartum hemorrhage secondary to uterine atony postdelivery which responded after a second-line uterotonic agent and insertion of a Bakri balloon tamponade. The massive primary postpartum hemorrhage required blood transfusion and was subsequently complicated with acute kidney injury. She was managed in the intensive care unit post-delivery and subsequently was transferred to the general ward.

She was nursed on a general ward for one week and discharged with antihypertension. At four weeks postpartum, she became normotensive, non-proteinuria, and her renal profile was normalized.

\section{Discussion}

Mirror syndrome, or Ballantyne syndrome, is

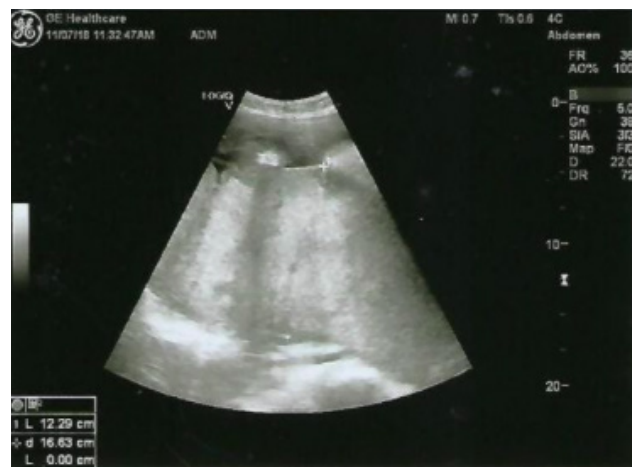

Figure 4: Transabdominal scan of hyperplacentosis (placenta thickness of $12.29 \mathrm{~cm}$ )

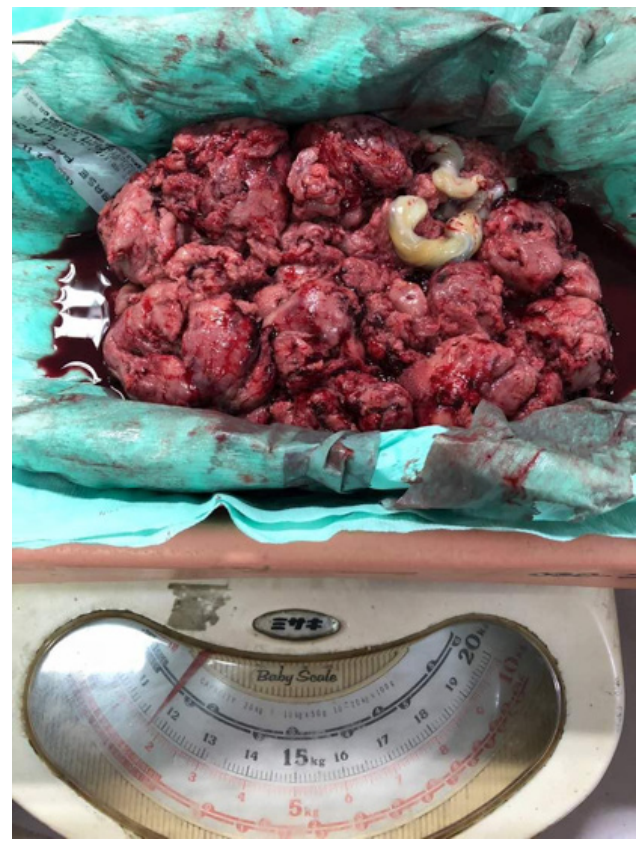

Figure 6: Placenta post-delivery weighing $1.8 \mathrm{~kg}$ which is more than a 1:6 ratio to fetal weight.

a rare clinical condition in pregnancy, which is characterized by fetal hydrops, placenta edema, and maternal edema. The syndrome mirrors the clinical fetal condition in the mother. The pathogenesis is unknown; however, a common hypothesis shared between mirror syndrome and preeclampsia is that a dysfunctional placenta releases anti-angiogenic factors into the maternal circulation. ${ }^{1}$ The incidence is about one case in 3,000 pregnancies; however, it could be under-reported as the clinical presentation is very similar to preeclampsia. ${ }^{2}$ In 1892 , John W. Ballantyne suggested that fetal hydrops was caused by Rhesus isoimmunization. However, a few years later, it was also found to be associated with mirror syndrome. In a retrospective study of 71 cases of fetal hydrops, mirror syndrome developed in $29 \%$ of the cases. ${ }^{3}$ A systematic review of associated fetal conditions, maternal presentation, and perinatal outcome concluded 
that mirror syndrome was associated with Rhesus isoimmunization (29\%), twin-twin transfusion syndrome (18\%), viral infection $(16 \%)$ and fetal malformations, fetal or placental tumors $(37.5 \%){ }^{4}$

The cause of fetal hydrops in our case is most likely due to a fetal heart abnormality leading to the development of mirror syndrome. The diagnosis was made late as it was not detected during follow-up. Ideally, all patients should be screened for fetal anomaly at 18 to 22 weeks gestation, as early detection of fetal anomalies at primary care would result in timely referral to an obstetrics and gynecology specialist for further management.

The presentation of mirror syndrome usually mimics preeclampsia. The onset of preeclampsia is generally after 20 weeks of gestation ${ }^{5}$ while in mirror syndrome, the onset ranged from 22.5 to 27.8 weeks of gestation. ${ }^{4}$ The presentation of mirror syndrome includes edema (80\%-100\%), hypertension $(57 \%-78 \%)$, and proteinuria $(20 \%-56 \%)$. The overall rate of intrauterine death was $56 \% .^{4}$ Maternal excessive weight gain with marked skin edema and uterine enlargement can also be distinguishable features in mirror syndrome. In contrast, elevated blood pressure and proteinuria can be present in both mirror syndrome and preeclampsia. ${ }^{5}$ Maternal symptoms disappeared 4.8 to 13.5 days after delivery. ${ }^{4}$

It is difficult to differentiate between preeclampsia and mirror syndrome from clinical assessment alone; however, hemodilution could be a main biological feature, differentiating mirror syndrome from usual preeclamptic syndromes. ${ }^{6}$ The hemoglobin, serum albumin levels, and uric acid are lower in mirror syndrome. The comparison between these conditions is summarized in Table $\mathbf{1}$

Table 1: Comparison between preeclampsia and mirror syndrome

\begin{tabular}{l|c|c|}
\hline \multicolumn{1}{|c|}{ Variable } & Mreeclampsia & Mirror syndrome \\
\hline Gestational age & More than 20 weeks of gestation & $16-34$ weeks of gestation \\
\hline Edema & Present & Markedly present \\
\hline Hypertension $(140 / 90)$ & Present & Not always present \\
\hline Proteinuria $(>300 \mathrm{mg} /$ day) & Present & Not always present \\
\hline Creatinine:urea ratio & Present & Not always present \\
\hline Thrombocytopenia & Present & Not always present \\
\hline Pulmonary edema & Present & Present \\
\hline Anemia & Hemoconcentration & Memodilution \\
\hline Placenta edema & Rare & Markedly present \\
\hline & Fetal & Polyhydramnios \\
\hline Hydrops & Rare & Present \\
\hline Amniotic fluid index & Oligohydramnios & Not always present \\
\hline Cardiac abnormality & Can be present & Present \\
\hline Intrauterine growth restriction & Usually present & Present \\
\hline Associated tumor & - & \\
\hline Fetal death & Not always present & \\
\hline
\end{tabular}

The fetal prognosis in established mirror syndrome is poor. The condition results in intrauterine fetal death in over $50 \%$ of cases. ${ }^{4}$ Case series add new evidence to support that early diagnosis of mirror syndrome, followed by fetal therapy and maternal clinical support, are critical for a good outcome. ${ }^{7}$ In those with an underlying correctable fetal anomaly or diseases such as fetal anemia and twin-to-twin transfusion syndrome, intervention during the antenatal period plays a vital role in the resolution of fetal condition and improves maternal and fetal outcome. The complications of mirror syndrome are pulmonary edema, acute respiratory distress syndrome, pericardial effusions, and renal failure. Pulmonary edema is the commonest complication and occurred in $21.4 \% .{ }^{4}$ In our case, the patient suffered from complications of mirror syndrome including severe preeclampsia, massive postpartum hemorrhage that required tamponade balloon institution, and blood transfusion. Following the 
complicated delivery, intrapartum, she had an acute renal injury and needed to be observed in the intensive care unit, and had hypertension in the early puerperium stage. Once the diagnosis of mirror syndrome is made, timely treatment is essential to achieve the best outcome for the mother. ${ }^{8}$

\section{Conclusion}

Early detection of the possible cause of fetal hydrops is very important and implementation of fetal therapy in a treatable cause, with consideration of early termination for other causes, may potentially decrease the risk of fetal mortality as well as maternal morbidity and mortality associated with mirror syndrome. Careful evaluation is needed to differentiate between preeclampsia and mirror syndrome because there may be a higher risk of maternal morbidity in mirror syndrome.

\section{How does this paper make a difference to general practice?}

- Excessive weight gain is commonly encountered during antenatal follow-up and should be investigated further.

- A fetal anomaly scan should be done at 18 to 22 weeks gestation to detect any structural anomalies in a primary setting with adequate ultrasound machine facilities and a skilled operator.

- Due to the similar clinical presentation of mirror syndrome and preeclampsia, it is crucial for early prompt recognition, identification of the cause, and early management of mirror syndrome. This will have an essential impact on maternal and fetal survival. Fetal therapy can be implemented in cases where the cause of mirror syndrome is treatable.

\section{References}

1. N. Graham, A. Garrod, P. Bullen, and A. E. P. Heazell, "Placental expression of antiangiogenic proteins in mirror syndrome: A case report," Placenta, vol. 33, no. 6, pp. 528-531, 2012, doi: 10.1016/j. placenta.2012.02.016.

2. S. Allarakia et al., "Characteristics and management of mirror syndrome: A systematic review (1956-2016)," J. Perinat. Med., vol. 45, no. 9. Walter de Gruyter GmbH, pp. 1013-1021, Dec. 20, 2017, doi: 10.1515/jpm-2016-0422.

3. G. Hirata, S. Aoki, K. Sakamaki, T. Takahashi, F. Hirahara, and H. Ishikawa, "Clinical characteristics of mirror syndrome: A comparison of 10 cases of mirror syndrome with non-mirror syndrome fetal hydrops cases," J. Matern. Neonatal Med., vol. 29, no. 16, pp. 2630-2634, 2016, doi: $10.3109 / 14767058.2015 .1095880$.
4. T. Braun et al., "Mirror syndrome: A systematic review of fetal associated conditions, maternal presentation and perinatal outcome," Fetal Diagn. Ther., vol. 27, no. 4, pp. 191-203, 2010, doi: $10.1159 / 000305096$.

5. S. F. Navarro-Perez, K. Corona-Fernandez, J. L. Rodriguez-Chavez, A. Bañuelos-Franco, and M. G. Zavala-Cerna, "Significant Clinical Manifestations in Ballantyne Syndrome, after a Case Report and Literature Review: Recognizing Preeclampsia as a Differential Diagnosis," Case Rep. Obstet. Gynecol., vol. 2019, pp. 1-7, 2019, doi: 10.1155/2019/2013506.

6. C. R. Mathias and C. Rizvi, "The diagnostic conundrum of maternal mirror syndrome progressing to preeclampsia - A case report," Case Rep. Womens Health, vol. 23, p. e00122, 2019, doi: 10.1016/j.crwh.2019.e00122.
7. A. Chimenea, L. García-Díaz, A. M. Calderón, M. M. D. Las Heras, and G. Antińolo, "Resolution of maternal Mirror syndrome after successful fetal intrauterine therapy: A case series," BMC Pregnancy Childbirth, vol. 18, no. 1, pp. 1-5, 2018, doi: 10.1186/s12884-018-1718-0.

8. H. Li and W. Gu, "Mirror syndrome associated with heart failure in a pregnant woman : a case report," Int J Clin Exp Med, vol. 8, no. 9, pp. 16132-16136, 2015. 